\title{
Diagnostic imaging for cervical spine clearance in multiple trauma patients - a comprehensive review
}

\author{
Mommsen P*, Clausen JD, Blossey R, Krettek C and Winkelmann M \\ Trauma Department, Hannover Medical School, 30625 Hannover, Germany
}

\begin{abstract}
Missed cervical spine injuries may have tremendous consequences in trauma patients. Thereby, multiple trauma patients are at special risk for cervical spine injuries. In awake and evaluable patients cervical spine could safely be cleared by clinical criteria even without any radiological imaging. In contrast, diagnostic imaging is mandatory in obtunded patients with relevant concomitant injuries. However, there is no validated diagnostic algorithm for the exclusion of cervical spine injuries in multiple trauma patients. Here, we present a comprehensive review of current literature and evidence concerning diagnostics for cervical spine clearance in adults suffering from blunt multiple trauma.
\end{abstract}

\section{Introduction}

Multiple trauma patients are at special risk for cervical spine injuries [1]. The incidence of cervical spine injuries in adult multiple trauma patients is up to $10 \%$ [2-5]. Concomitant traumatic brain injury and maxillofacial lesions represent relevant risk factors for cervical spine injuries [6-11]. In awake and evaluable patient's cervical spine could safely be cleared by clinical criteria even without any radiological imaging according to the Canadian C-spine rule and NEXUS (National Emergency X-Radiography Utilization Study) criteria [12-15]. Due to painful and awareness affecting injuries as well as preclinical procedures like intubation these clinical criteria are not applicable in multiple trauma patients $[16,17]$. Accordingly, diagnostic imaging is mandatory in these patients in order to rule out cervical spine injuries.

\section{Diagnostic imaging}

Based on current literature there is no validated diagnostic gold standard for cervical spine clearance in multiple trauma patients [18]. As a result, a broad variety of diagnostic algorithms exists for cervical spine clearance [19]. There is only a consensus about the diagnostic superiority of computer tomography (CT) compared to conventional $\mathrm{x}$-ray diagnostics [20]. In general, CT-scan is recommended in multiple trauma due to its higher diagnostic accuracy and timely clarification of cervical spine [21-27]. The question whether cervical spine could be sufficiently cleared by solitary CT or whether additional imaging procedures are needed, e.g. magnetic resonance imaging (MRI) or functional $\mathrm{x}$-ray imaging, is controversially discussed [28]. According to the high negative predictive value of CT for cervical spine injuries current studies suggest that solitary CT is adequate for the exclusion of cervical spine injuries, even ligament instabilities. In a prospective study of 9.227 patients Duane et al. reported a $100 \%$ negative predictive value of CT for cervical spine injuries [19]. With a negative predictive value of $99.97 \%$ Inaba et al. described comparable results in a prospective multi-centre study of 10.276 patients [29]. These results are supported by current meta-analyses reporting cervical spine injuries despite inconspicuous CT-scan only in $0-0.3 \%[18,30]$. Comparable rates of false negative CT-scans of $0.04-1.09 \%$ were found in further retrospective and prospective studies [31-33]. In a prospective study by Berne et al. and in a retrospective study by Steigelman et al. with a relatively small number of cases (85 and 120 patients) a higher amount of false negative CT-scans of $5-5.8 \%$ was found $[5,21]$. Due to an even higher proportion of false negative CT-scans of $22 \%$ in a prospective study of 1.577 patients Diaz et al. suggested that CT safely exclude bony lesions, but not ligament injuries of the cervical spine [34]. Most of the cited studies obtain their results concerning the diagnostic accuracy of CT in regard to additionally conducted MRI as reference imaging procedure. In general, magnetic resonance imaging plays a tangential role as a diagnostic tool in the acute phase of multiple trauma management due to lack of time and logistical reasons. Substantial indications for MRI scanning are neurological deficits. Besides spinal cord injuries, ligament lesions and damaged intervertebral discs could be excluded by MRI [22,35,36]. However, the clarification of ligament injuries of the cervical spine was found to be unnecessary in a prospective study by Patton et al. due to the low incidence [37]. Alternatively, traction or functional x-ray imaging of the cervical spine could be performed in order to rule out ligament injuries [38-41]. Sliker et al. found no significant differences between $\mathrm{MRI}$ and functional $\mathrm{x}$-ray imaging regarding the accuracy in diagnosing ligament lesions of the cervical spine [42]. Nevertheless, the routine and selective use of functional $\mathrm{x}$ - ray imaging also seems to be questionable as pathological findings are rare [43-45].

\section{Conclusion}

Up to date there is no validated diagnostic gold standard for cervical spine clearance in multiple trauma patients. Based on the current literature cervical spine could be sufficiently cleared, even for

Correspondence to: Philipp Mommsen MD, Trauma Department, Hannover Medical School, Carl-Neuberg-Strasse 1, 30625 Hannover, Germany, E-mail: mommsen.philipp@mh-hannover.de

Key words: cervical spine clearance, diagnostics, imaging, multiple trauma

Received: March 24, 2018; Accepted: April 06, 2018; Published: April 09, 2018 
ligament injuries, by CT without any further diagnostic imaging. MRI plays an additional role in clarification of neurological deficits.

\section{Authorship and contributorship}

All authors have made substantial contributions to 1) conception and design, or acquisition of data, or analysis and interpretation of data; 2) drafting the article or revising it critically for important intellectual content; 3) final approval of the version to be published; and 4) agreement to act as guarantor of the work (ensuring that questions related to any part of the work are appropriately investigated and resolved).

\section{Conflicts of interest}

There is no conflict of interest. All authors disclose any financial or nonfinancial competing interests. The presentation of the issue is independent.

\section{References}

1. Albrecht RM, Malik S, Kingsley DD, Hart B (2003) Severity of cervical spine ligamentous injury correlates with mechanism of injury, not with severity of blunt head trauma. Am Surg 69: 261-265. [Crossref]

2. Ross SE, O'Malley KF, DeLong WG, Born CT, Schwab CW (1992) Clinical predictors of unstable cervical spinal inhury in multiply injured patients. Injury 23: 317-319. [Crossref]

3. Grossmann MD, Reilly PM, Gillett T, Gillett D (1999) National survey of the incidence of cervical spine injury and approach to cervical spine clearance in U.S. trauma centers. J Trauma 47: 684-690. [Crossref]

4. Buhren V (2002) [Fractures and instability of the cervical spine. Unfallchirurg 105: 1049-1066. [Crossref]

5. Steigelman M, Lopez P, Dent D, Myers J, Corneille M et al. (2008) Screening cervical spine MRI after normal spine CT scans in patients in whom cervical spine injury cannot be excluded by physical examination. Am J Surg 196: 857-862. [Crossref]

6. Blackmore CC, Emerson SS, Mann FA, Koepsell TD (1999) Cervical spine imaging in patients with trauma: determination of fracture risk to optimize use. Radiology 211 759-765. [Crossref]

7. Hackl W, Fink C, Hausberger K, Ulmer H, Gasner R (2001) The incidence of combined facial and cervical spine injuries. $J$ Trauma 50: 41-45. [Crossref]

8. Hills MW, Deane SA (1993) Head injury and facial injury: is there an increased risk of cervical spine injury? J Trauma 34: 549-553. [Crossref]

9. Iida H, Tachibana S, Kitahara T, Horiike S, Ohwada T, et al. (1999) Association of head trauma with cervical spine injury, spinal cord injury, or both. J Trauma 46: 450-452. [Crossref]

10. Mulligan RP, Friedman JA, Mahabir RC (2010) A nationwide review of the associations among cervical spine injuries, head injuries, and facial fractures. J Trauma 68: 587- 592. [Crossref]

11. Reich W, Surov A, Eckert AW (2016) Maxillofacial trauma - Underestimation of cervical spine injury. J Craniomaxillofac Surg 44: 1469-1478. [Crossref]

12. Bandiera G, Stiell IG, Wells GA, Clement C, De Maio V, et al. (2003) The Canadian $\mathrm{C}$-spine rule performs better than unstructured physician judgment. Ann Emerg Med 42: 395-402. [Crossref]

13. Hoffman JR, Mower WR, Wolfson AB, Todd KH, Zucker MI, et al. (2000) Validity of a set of clinical criteria to rule out injury to the cervical spine in patients with blunt trauma. National Emergency X-Radiography Utilization Study Group. $N$ Engl J Med 343: 94-99. [Crossref]

14. Stiell IG, Clement CM, McKnight RD, Brison R, Schull MJ, et al. (2003) The Canadian $\mathrm{C}$-spine rule versus the NEXUS low-risk criteria in patients with trauma. $N$ Engl J Med 349: $2510-2518$

15. Stiell IG, Wells GA, Vandemheen KL, Clement CM, Lesiuk H, et al. (2001) The Canadian C- spine rule for radiography in alert and stable trauma patients. JAMA 286 1841-1848. [Crossref]

16. Chang CH, Holmes JF, Mower WR, Panacek EA (2005) Distracting injuries in patients with vertebral injuries. J Emerg Med 28: 147-152. [Crossref]

17. Ullrich A, Hendey GW, Geiderman J, Shaw SG, Hoffman J, et al. (2001) Distracting painful injuries associated with cervical spine injuries in blunt trauma. Acad Emerg Med 8: 25-29. [Crossref]
18. Raza M, Elkhodair S, Zaheer A, Yousaf S (2013) Safe cervical spine clearance in adult obtunded blunt trauma patients on the basis of a normal multidetector CT scan - a meta- analysis and cohort study. Injury 44: 1589-1595. [Crossref]

19. Duane TM, Young AJ, Vanguri P, Wolfe LG, Katzen J, et al. (2016) Defining the cervical spine clearance algorithm: A single-institution prospective study of more than 9,000 patients. J Trauma 81: 541-547. [Crossref]

20. Antevil JL, Sise MJ, Sack DI, Kidder B, Hopper A, et al. (2006) Spiral computed tomography for the initial evaluation of spine trauma: A new standard of care? $J$ Trauma 61: 382-387. [Crossref]

21. Berne JD, Velmahos GC, El-Tawil Q, Demetriades D, Asensio JA, et al. (1999) Value of complete cervical helical computed tomography scanning in identifying cervical spine in the unevaluable blunt trauma patient with multiple injuries. J Trauma 47: 896- 902. [Crossref]

22. Crim JR, Moore K, Brodke D (2001) Clearance of the cervical spine in multitrauma patients: the role of advanced imagin. Semin Ultrasound CT MR 22: 283-305. [Crossref]

23. Harris MB, Kronlage SC, Carboni PA, Robert KQ, Menmuir B, et al. (2000) Evaluation of the cervical spine in the polytrauma patient. Spine (Phila Pa 1976) 25: 2884- 2891. [Crossref]

24. Holmes JF, Akkinepalli R (2005) Computed tomography versus plain radiography to screen for cervical spine injury: a meta-analysis. J Trauma 58: 902-905. [Crossref]

25. Link TM, Schuierer G, Hufendiek A, Peters PE, (1994) Fractures of the cervical spine. Diagnosis in multiple trauma patients. Radiologe 34: 721-727. [Crossref]

26. Platzer P, Jaindl M, Thalhammer G, Dittrich S, Wieland T, et al. (2006) Clearing the cervical spine in critically injured patients: a comprehensive C-spine protocol to avoid unnecessary delays in diagnosis. Eur Spine J 15: 1801-1810. [Crossref]

27. Schenarts PJ, Diaz J, Kaiser C, Carrillo Y, Eddy V, et al. (2001) Prospective comparison of admission computed tomographic scan and plain films of the upper cervical spine in trauma patients with altered mental status. $J$ Trauma 51: 663-668. [Crossref]

28. Como JJ, Diaz JJ, Dunham CM, Chiu WC, Duane TM, et al. (2009) Practice management guidelines for identification of cervical spine injuries following trauma update from the eastern association for the surgery of trauma practice management guidelines committee. J Trauma 67: 651-659. [Crossref]

29. Inaba K, Byerly S, Bush LD, Martin MJ, Peck KA, et al. (2016) Cervical spine clearance: A prospective Western Trauma Association Multi-Institutional Trial. $J$ Trauma 81: 1122-1130. [Crossref]

30. Patel MB, Humble SS, Cullinane DC, Day MA, Jawa RS, et al. (2015) Cervical spine collar clearance in the obtunded adult blunt trauma patient: a systematic review and practice management guideline from the Eastern Association for the Surgery of Trauma. J Trauma 78: 430-441. [Crossref]

31. Harris TJ, Blackmore CC, Mirza SK, Jurkovich GJ (2008) Clearing the cervical spine in obtunded patients. Spine (Phila Pa 1976) 33: 1547-1553. [Crossref]

32. Sanchez B, Waxman K, Jones T, Connor S, Chung R, et al. (2005) Cervical spine clearance in blunt trauma: evaluation of a computed tomography-based protocol. $J$ Trauma 59: 179-183. [Crossref]

33. Hogan GJ, Mirvis SE, Shanmuganathan K, Scalea TM (2005) Exclusion of unstable cervical spine injury in obtunded patients with blunt trauma: is MR imaging needed when multi- detector row CT findings are normal? Radiology 237: 106-113. [Crossref]

34. Diazz JJ, Aulino JM, Collier B, Roman C, May AK, et al. (2005) The early work-up for isolated ligamentous injury of the cervical spine: does computed tomography scan have a role? J Trauma 59: 897-903.

35. Katzberg RW, Benedetti PF, Drake CM, Ivanovic M, Levine RA, et al. (1999) Acute cervical spine injuries: prospective MR imaging assessment at a level 1 trauma center. Radiology 213: 203-212.

36. Ghanta MK, Smith LM, Polin RS, Marr AB, Spires WV, et al. (2002) An analysis of Eastern Association for the Surgery of Trauma practice guidelines for cervical spine evaluation in a series of patients with multiple imaging techniques. Am Surg 68: 563-567.

37. Patton JH, Kralovich KA, Cuschieri J, Gasparri M (2000) Clearing the cervical spine in victims of blunt assault to the head and neck: what is necessary? Am Surg 66: 326330. [Crossref]

38. Sees DW, Rodriguez Cruz LR, Flaherty SF, Ciceri DPThe, et al. (1998) use of bedside fluoroscopy to evaluate the cervical spine in obtunded trauma patients. J Trauma 45 768- 771 .

39. Lewis LM, Docherty M, Ruoff BE, Fortney JP, Keltner RA, et al. (1991) Flexion-extension views in the evaluation of cervical-spine injuries. Ann Emerg Med 20: 117-121. 
40. Davis JW, Parks SN, Detlefs CL, Williams GG, Williams JL, et al. (1995) Clearing the cervical spine in obtunded patients: the use of dynamic fluoroscopy. J Trauma 39: 435-438. [Crossref]

41. Ajani AE, Cooper DJ, Scheinkeste CD, Laidlaw J, Tuxen DV, et al. (1998) Optimal assessment of cervical spine trauma in critically ill patients: a prospective evaluation. Anaesth Intensive Care 26: 487-491.

42. Sliker CW, Mirvis SE, Shanmuganathan (2005) Assessing cervical spine stability in obtunded blunt trauma patients: review of medical literature. Radiology 234: 733-739. [Crossref]
43. Anglen J, Metzler M, Bunn P, Griffiths H (2002) Flexion and extension views are not cost- effective in a cervical spine clearance protocol for obtunded trauma patients. $J$ Trauma 52: 54-59. [Crossref]

44. Griffiths HJ, Wagner J, Anglen J, Bunn P, Metzler M, et al. (2002) The use of forced flexion/extension views in the obtunded trauma patients. Skeletal Radiol 31: 587-591. [Crossref]

45. Pollack CV, Hendey GW, Martin DR, Hoffman JR, Mower WR, et al. (2001) Use of flexion- extension radiographs of the cervical spine in blunt trauma. Ann Emerg Med 38: 8-11. [Crossref]

Copyright: (C2018 Mommsen P. This is an open-access article distributed under the terms of the Creative Commons Attribution License, which permits unrestricted use, distribution, and reproduction in any medium, provided the original author and source are credited. 